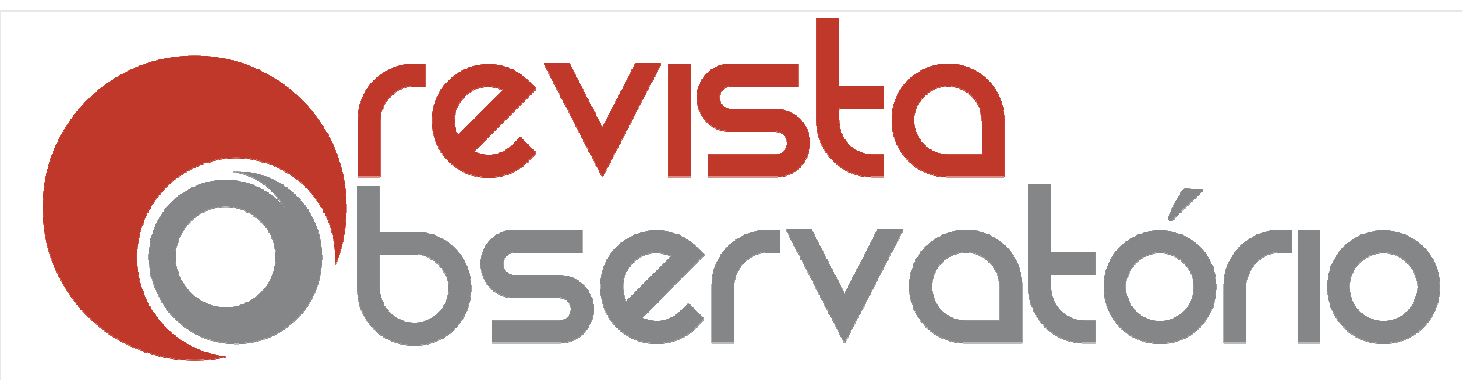

ISSN n² 2447-4266

Vol. 4, n. 1, Janeiro-Março. 2018

DOI: http://dx.doi.org/10.20873/uft.2447-4266.2018v4n1p42

\title{
A VERDADE SEM REPRESENTAÇÃO
}

THE TRUTH WITHOUT

REPRESENTATION

LA VERDAD SIN

REPRESENTACIÓN

\section{Maria dos Remédios de Brito ${ }^{1,2}$}

\section{RESUMO}

Há na cena filosófica uma exclusão da aparência, pois a verdade é um conceito fundamental para a filosofia. No cenário contemporâneo tal conceito é posto em questionamento como valor filosófico. É Nietzsche quem faz uma reversão do valor da verdade como essência, como representação universal, com ele a verdade tem ligações com a vida e suas avaliações. O texto elabora algumas notas sobre essa questão, destacando o conceito de verdade e pontuando motivações que levam o temor ao ficcional.

PALAVRAS-CHAVE: Verdade; Nietzsche; Ficcional.

\section{ABSTRACT}

There is, in the philosophical scenario, an exclusion of the appearance, because the truth is a fundamental concept in philosophy. In the contemporary world,

\footnotetext{
${ }^{1}$ Graduada em Filosofia pela Universidade Federal do Pará, mestrado e doutorado em Filosofia da Educação pela Universidade Metodista de Piracicaba (UNIMEP), pós-doutora em Filosofia da Educação pela Universidade Estadual de Campinas; professora da Universidade Federal do Pará. E-mail: mrb@ufpa.br/mrdbrito@hotmail.com.

2 Endereço de contato da autora (por correio): Universidade Federal do Pará, Instituto de Educação Matemática e Científica. Rua: Augusto Corrêa, Guamá, CEP: 66075-110 - Belem, PA Brasil.
} 


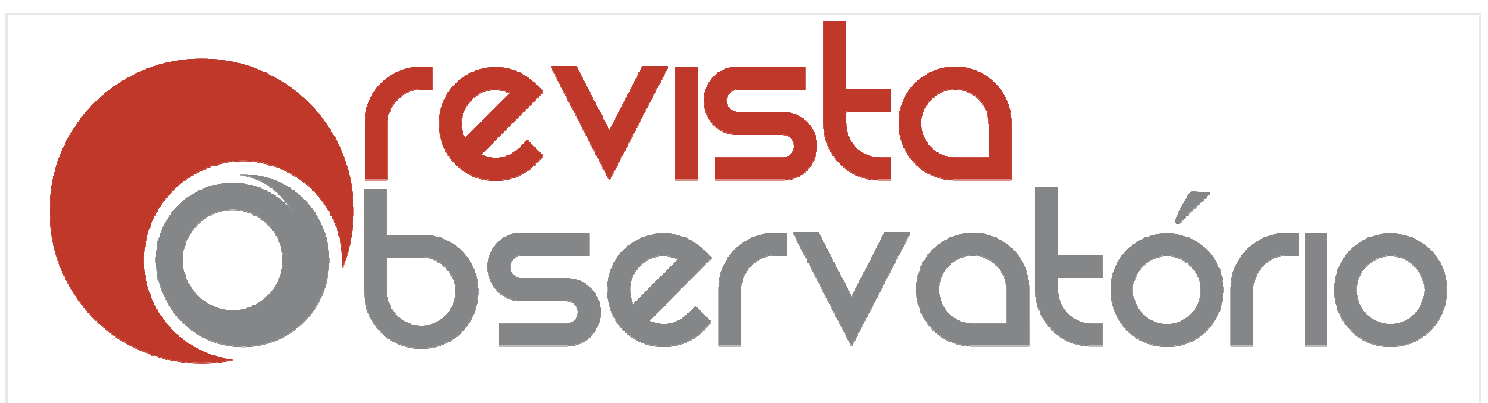

ISSN n² 2447-4266

Vol. 4, n. 1, Janeiro-Março. 2018

DOI: http://dx.doi.org/10.20873/uft.2447-4266.2018v4n1p42

the approach of such concept as philosophical value is questioned. Nietzsche is the one who reverses the value of the truth as an essence, as a universal representation, the truth for him is linked to life and its evaluations. The text elaborates some notes about this question, highlighting the concept of truth and pointing out motives that take fear to fiction.

KEYWORDS: Truth; Nietzsche; Fiction.

\section{RESUMEN}

Existe la escena filosófica una exclusión de la apariencia, porque la verdad es un concepto fundamental para la filosofía. En el entorno contemporáneo tal concepto se pone en cuestión como un valor filosófico. Es Nietzsche que es una reversión del valor de la verdad como esencia y como una representación universal, con la que en realidad tiene lazos con la vida y sus evaluaciones. El texto desarrolla algunas notas sobre este tema, destacando el concepto de verdad y puntuando las motivaciones que conducen al temor de ficción.

PALABRAS CLAVE: Verdad; Nietzsche; Ficticio.

Recebido em: 05.10.2017. Aceito em: 01.12.2017. Publicado em: 01.01.2018. 


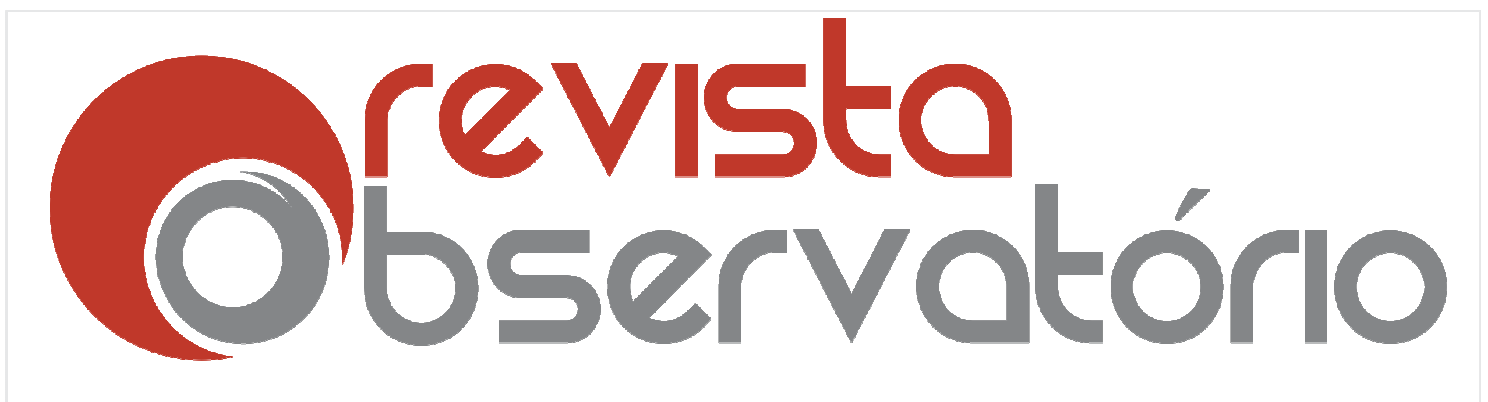

ISSN n² 2447-4266

Vol. 4, n. 1, Janeiro-Março. 2018

DOI: http://dx.doi.org/10.20873/uft.2447-4266.2018v4n1p42

A "Verdade" tem uma longa história no campo da filosofia ocidental e é um conceito muito caro que prima por um saber último e primeiro. Atingir a verdade é buscar a adequação, assim como sua automanifestação. A concepção de "Verdade" posta pela tradição produz oposições entre verdadeiro e falso, aparência e essência. Isso é posto por entender que "aquilo que as coisas são é o que não são não é" (ABBAGNANO, 2000, p. 994), tomando como referência a concepção platônica.

[...] fica evidente que as coisas possuem alguma substância fixa que lhes é própria, a qual não guarda relação conosco nem é causada por nós; não variam, oscilando de uma forma ou de outra segundo nos parecem, mas existem por si mesmas relativamente a sua própria substância que lhes é inerente por natureza (PLATÃO, 2010, Crátilo, 386 e).

Então também no nomear, se pretendemos ser coerentes com o que já concluímos, não podemos agir segundo nossa própria vontade, devendo, ao contrário, empregar a maneira e a ferramenta determinadas pela natureza das coisas (PLATÃO, 2010, Crátilo, 387 e).

[...] Crátilo está certo ao afirmar que os nomes dizem respeito às coisas por natureza e que nem todos são artesãos produtores de nomes, mas somente o indivíduo que mantém em vista o nome que pertence naturalmente a cada coisa particular e que é capaz de incorporar sua Forma (/deia) nas letras e sílabas (PLATÃO, 2010, Crátilo, 390 e).

Nessa acepção, a verdade abriga o ser, o que conserva uma forma, uma Ideia, a natureza da coisa particular (a essência, o que é) e o não verdadeiro, o não ser (a aparência, a cópia, o sensível, perecível), podendo ser agregado tal ideia no emprego dos nomes, nos objetos, nos eventos. Platão (2003), em seu 


\title{
revisto
}

ISSN n² 2447-4266

Vol. 4, n. 1, Janeiro-Março. 2018

DOI: http://dx.doi.org/10.20873/uft.2447-4266.2018v4n1p42

Diálogo "Parmênides", vai desenvolver uma curiosa teoria das Formas (Ideias) que não configura nem materialidade e nem percepções, mas que as coisas materias e perceptíveis apenas fazem participação. Com esse pensador, a essência, o inteligível, o perene recebe grau fundamental de entendimento. A verdade, nesse sentido, é aquilo que compõe a forma, a Ideia, o que permanece e é.

No momento, será ponderada a teoria da verdade como correspondência, pois é a noção mais usada e mais divulgada que tem sua configuração em Platão. Para exemplificar tal teoria que expressa a verdade como representação dos juízos na constituição dos objetos, cito:

\begin{abstract}
Verdade, em sentido estrito, significa uma propriedade das proposições, dos juízos mais próximos em que se expressa algo sobre a constituição dos objetos, dos eventos, dos estados e dos fenômenos. A questão acerca de quais critérios de verdade podem ser empregados desempenha um papel central. À diferença das questões da verdade há pouco discutidas, trata-se aqui do âmbito das teorias da verdade em sentido estrito (por exemplo, da teoria correspondência, ou da teoria da redundância da verdade). A forma defendida e dominante mais corrente da teoria da verdade é a teoria da correspondência. Ela está mais próxima também de nosso entendimento do cotidiano. A posição fundamental da teoria da correspondência é a de que uma proposição (um juízo, uma representação) só e somente só é verdadeira quando concorda com a parte correspondente da realidade - quando, portanto, há correspondência entre a proposição (o juízo, a representação) e o mundo, não importando se essa relação é pensada como isomorfismo ou como reprodução de qualquer tipo (ABEL, G. 2002, p.18- 19).
\end{abstract}

Contudo, não se pode explicar efetivamente como se configura a verdade como adequação entre o pensamento e os objetos sem que se leve em consideração os signos, visto que eles conduzem para a ideia de que existe um mundo já fabricado ou que há um sujeito prévio (ABEL, G. 2002). Do mesmo modo, a automanifestação também soa esquisito, na medida em que somos 


\section{Observatónio}

ISSN n² 2447-4266

Vol. 4, n. 1, Janeiro-Março. 2018

DOI: http://dx.doi.org/10.20873/uft.2447-4266.2018v4n1p42

seres humanos. Um suposto objeto individual só configura sentido se estiver ligado a esquemas intelectivos, a signos e a interpretações (ABEL, G. 2002).

Nietzsche é o pensador que faz a revirada desse sentido e modifica o conteúdo e o esquema representacional em que tal leitura é posta. Ele coloca em evidência a "vontade de verdade", pois a vontade de imprimir a verdade como adequação é nada mais do que uma estratégia para afirmar e confirmar a fixidade, que nada mais é do que um componente moral e valorativo.

O pensador alerta que não há a verdade em si, que não há uma verdade pré-estabelecida, firmada como absoluta, ou adequação do pensamento à coisa pensante, ao contrário, aquilo que se denomina verdade está envolta por aparatos inventivos, criativos, culturais, sociais e morais (MACHADO, R. 1999). Não há descoberta de uma essência, uma unidade, uma natureza formalizada, não há nada escondido atrás de véus e máscaras pré-definidas, mas tudo perpassa pela produção humana. A verdade é demasiadamente humana, portanto, não deixa de ser interpretação.

Nietzsche é um filósofo que pretende alertar para as pretensas Verdades acabadas, do mesmo modo que põe à crítica aquilo que se chama de conhecimento lógico, que busca sínteses e acabamentos, pois esses esquemas conceituais impedem o homem de viver com plenitude e comando, já que o cerca por uma razão teorética que tenta, a todo custo, encontrar verdades fixas. A busca pela verdade, por meio da lógica, termina negligenciando a força, a criatividade com que o homem poderia apreender a vida no que há de belo e no que há de assustador na existência, assim como no que há de ilógico e enganoso.

Nietzsche entende que seja muito difícil viver no turbilhão da vida, sem garantias, sem certezas, em que nada é fixo e sólido. Por isso, a cultura e as 


\section{revisto}

ISSN n² 2447-4266

Vol. 4, n. 1, Janeiro-Março. 2018

DOI: http://dx.doi.org/10.20873/uft.2447-4266.2018v4n1p42

instituições tendem, de todas as formas, educar, para buscar um futuro, uma vida calma, tranquila, serena, segura, que pudesse ser sentida com paz e felicidade. Tudo isso gera uma procura, para sentir o ser das coisas, a verdade em si, a permanência de uma vida sem dores e sem conflitos. O fundo metafísico que ronda a ideia de verdade é muito apreciado por alguns, por remeter à tranquilidade, mas Nietzsche entende que a "vontade de verdade" estabelece limites para um pequeno prazer, para um pequeno desejo de comodidade, e a vida é esquecida, negligenciada, sendo vista por um olhar triste e severo.

\section{II}

O filósofo insiste na crítica na dicotomia metafísica verdade e aparência, a partir do conceito de "vontade de verdade" ou "instinto de verdade" (MACHADO, R. 1999). O autor pondera a seguinte questão: o conhecimento não faz parte de uma natureza humana; Aristóteles (2002), em seu livro "Metafísica", afirma que todos os homens naturalmente desejam o conhecimento. Não há instinto humano natural para a verdade, para o conhecimento, ou a verdade não é de natureza dos instintos.

O conceito de verdade foi produzido, criado, inventado. No texto "Verdade e mentira no sentido extramoral", Nietzsche inicia com uma fábula sobre o conhecimento, que pode ser bem ilustrativa para o que se deseja demonstrar.

Em algum ponto do universo inundado por cintilações de inúmeros sistemas solares houve um dia um planeta em que animais inteligentes inventaram o conhecimento. Foi o minuto mais orgulhoso e mais mentiroso da "história universal", mas foi apenas um minuto. Depois de alguns suspiros da natureza o planeta se congelou e os animais inteligentes tiveram que morrer (NIETZSCHE, 1997, p. 213, tradução levemente modificada). 


\section{Observatónio}

ISSN n² 2447-4266

Vol. 4, n. 1, Janeiro-Março. 2018

DOI: http://dx.doi.org/10.20873/uft.2447-4266.2018v4n1p42

Ora, o que Nietzsche conta é que não há conhecimento, verdade naturalizada, pronta para ser descoberta, desvelada, assim, como não há um instinto para o conhecimento, ou seja, não se deve definir o homem pela possibilidade de conhecimento, visto que os instintos são muito mais importantes do que o saber, do que a verdade.

A "vontade de verdade" é o desejo de impor um saber, ou mesmo uma crença sobre a verdade. Essa vontade não remete à posse do que seja o verdadeiro, mas apenas a suposição de posse. Toda posse passa somente por uma convicção de possuir o conhecimento verdadeiro, assim como o sentimento de obter a verdade vem dessa crença, ou de uma fé e não da possibilidade de ter a verdade em si (MACHADO, R. 1999). É por isso que Nietzsche faz ligações do conceito de "vontade de verdade", ou "instinto de verdade", com as questões políticas, sociais, culturais e educacionais, pontuando uma estreita relação entre verdade e valor moral.

A crença, na verdade, é fundamental para o homem que vive gregariamente, pois é com o advento da sociedade que se exige a necessidade da verdade. Dessa forma, o conhecimento, para ser plausível, precisa ser configurado como um saber verdadeiro, mostrar clareza e definições. A mesma coisa acontece diante das relações humanas. Para que um cidadão confie um no outro, ou mesmo demonstre respeito e confiança, ele elege a lealdade, a verdade.

Neste caso, a sociedade e os homens, em geral, menosprezam a inverdade, ou seja, tudo aquilo que possa parecer falso, aparente e enganoso. Isso não pode ser traduzido como confiança, mesmo sabendo-se que muitas vezes se utiliza a mentira, ou para afirmar-se de uma forma, ou para aparentar- 


\section{frevisto}

ISSN n² 2447-4266

Vol. 4, n. 1, Janeiro-Março. 2018

DOI: http://dx.doi.org/10.20873/uft.2447-4266.2018v4n1p42

se uma coisa que não é. Mas, se fosse, poderia ser aceito socialmente, ou pelo medo de que, sendo o que se é, se fosse rejeitado.

O que parece interessar é que sempre o homem procura afirmar a verdade como superior à aparência. Ora, Nietzsche indaga: o que leva a verdade ser superior à aparência? Ele coloca em suspeita quando questiona, por entender que essas duas perspectivas não podem ser vistas como excludentes; a inverdade, a aparência, o falso, o ilusório fazem parte da existência humana, mas a vaidade humana e seus interesses impulsionam o homem para uma crença numa existência, ou em um conhecimento verdadeiro.

O falar nas costas dos outros, o representar, o viver no brilho emprestado ou usar uma máscara, a convenção que oculta o jogo de cena diante dos outros e de si próprio, numa palavra, o esvoaçar constante em torno dessa chama única, a vaidade, são de tal modo a regra e a lei que não há quase nada mais inconcebível do que o aparecimento de um impulso honesto e puro para a verdade (NIETZSCHE, 1997, p. 216).

Então, a existência social produz a necessidade para uma "vontade de verdade" estando ligada ao próprio meio de viver culturalmente. O seu exercício frequente torna-se uma exigência, assim como é importante criar ações que possam ser vistas e valoradas como verdadeiras e boas. Por outro lado, sob o fundo do que seja aparente, mentiroso se vai criando a verdade em seu estado de sociedade. Assim, a sociedade necessita fixar leis, normas, valores que estão efetivamente ligados à linguagem. Cria-se toda uma gramática legisladora que estabelece comandos, designações uniformes que possam ser válidas universalmente, assim como essa mesma gramática precisa vulgarizar palavras, expressões para estabelecer certos códigos lógicos. Com isso, o mentiroso é aquele

que utiliza as palavras, as designações pertinentes, para fazer o irreal parecer real. É esta conversão que estabelece a verdade. A verdade não é uma adequação ao intelecto à realidade; é o resultado de uma 


\section{revisto}

ISSN n² 2447-4266

Vol. 4, n. 1, Janeiro-Março. 2018

DOI: http://dx.doi.org/10.20873/uft.2447-4266.2018v4n1p42

convenção que é imposta com o objetivo de tornar possível a vida social; é uma ficção necessária ao homem em suas relações com os outros homens [...] O homem não ama necessariamente a verdade: deseja suas consequências favoráveis. $O$ homem também não odeia a mentira; não suporta os prejuízos por ela causados. O que se proscreve, o que não se aceita e não se deseja é o que é considerado nocivo: são as consequências nefastas tanto da mentira quanto da verdade. A obrigação, o dever de dizer a verdade nasce para antecipar as consequências nefastas da mentira. Quando a mentira tem valor agradável ela é muito bem permitida (MACHADO, R. 1999. p. 38, grifo meu).

É possível notar que a questão da verdade em Nietzsche vai muito além da perspectiva epistemológica, para entremear reflexões de ordem cultural, social e política. Seu objetivo fundamental é destacar que a verdade, a aparência, o verdadeiro, o falso, estão ligados à moral, do mesmo modo, que não é possível deixar de pontuar que tal problemática diz respeito à coexistência humana em sua vivência gregária, na tentativa de buscar a ordem, as leis, as exigências que possam manter o homem em segurança, em equilíbrio e na paz.

Mas também é importante ressaltar que no texto "Sobre a verdade e a mentira no sentido extramoral", essa ligação com a moral não remete ao estudo de uma teoria da moral, como bem salienta Machado (1999). Nietzsche elabora seu argumento sobre a verdade e a mentira a partir de um pathos extramoral, que fomenta ligações com aquilo que ele desenvolverá posteriormente: a fisiologia. É no sentido extramoral que o pensador liga vontade, instinto de verdade, de conhecimento e até mesmo de ilusão, na tentativa de despontar que o homem também necessita da não verdade, do não saber. Aquilo que se pode denominar socialmente como verdade pode ter o mesmo valor da não verdade, do aparente, do falso, do ilusório. Sobretudo, Nietzsche quer martelar a oposição metafísica do verdadeiro e do falso, de essência e de aparência. 


\section{Observatónio}

ISSN n² 2447-4266

Vol. 4, n. 1, Janeiro-Março. 2018

DOI: http://dx.doi.org/10.20873/uft.2447-4266.2018v4n1p42

\section{III}

Com isso, o sentido extramoral solicita uma perspectiva artística, pois o conhecimento é para Nietzsche (1997) uma força de superfície e que por isso também é subjetivo. $O$ homem não pode atingir a própria coisa, o mundo é uma ilusão e que nós o interpretamos ao nosso modo. Se a ciência, por exemplo, tem uma pretensão à verdade se opondo a todo tipo de saber aparente, a arte é o domínio da aparência; com ela não se fala em oposições, mas em criação e invenção. A arte se diferencia da ciência por entender que a vida é aparência, ela, então, está ao lado da vida, por que a vida afirma as ilusões, os véus e as máscaras.

O intelecto humano é o principal artista, visto que nem a ciência, nem o conhecimento lógico, nem a consciência podem estabelecer o centro de um saber verdadeiro. Aquilo que se pode chamar de consciência ou mesmo de um centro racional, se ocupa de disfarces, controversas, não é o lugar da segurança. Para Nietzsche, isso não é nenhum pouco problemático, ao contrário, o seu poder de criar, de disfarçar, é artístico e isso deve ser estimulado. Se a consciência, ou mesmo o intelecto têm esse poder inventivo, poético, é possível criar uma linguagem capaz de movimentar a sensibilidade humana para uma perspectiva estética. Dessa maneira, rasgam-se os véus das certezas e das verdades e o corpo, a vida, se deixam levar pelo ato criador, permitindo que o homem invente para si modos vitais e diminua a miséria da vida.

Não se pode alcançar uma suposta realidade nem abaixo e nem acima do homem, não é possível chegar à essência das coisas; o fundamental é que o intelecto possa usar a própria força artística transformadora para configurar novos sentidos à existência. Esse labor estético possibilita construir e criar maneiras de vidas e de experiências que sejam afirmativas. A arte, para 


\section{Observatónio}

ISSN n² 2447-4266

Vol. 4, n. 1, Janeiro-Março. 2018

DOI: http://dx.doi.org/10.20873/uft.2447-4266.2018v4n1p42

Nietzsche (1992), é uma força criadora da existência, que pode permitir ao homem o esquecimento da tirania do pensar lógico formal e abra caminho para um saber, um conhecimento que tenha ligações com a vida e com a existência.

Por instantes, o homem pode sair das paredes mórbidas da verdade e dar realmente valor ao não saber, no qual a filosofia e a ciência possam ser entendidas como saberes em perspectivas e em interpretações. O filósofo, para Nietzsche (1969), não seria nada mais do que um artista, na medida em que a realidade não seria para ele mais do que um experimentalismo e um perspectivismo, não escondendo nenhum tipo de fundamento. Isso permite que o filósofo sorria da realidade e, fundamentalmente, da pretensa certeza, como fala Fink (1988). O filósofo artista sente a vida, o mundo, com maior jovialidade, alegria, pois se opõe à pretensão dogmática e às coisas absolutas.

Para Nietzsche, a arte é maneira de liberar o intelecto, pois com ela o ato criador torna-se demasiadamente humano, pode ser exercitado sem horror e medo. Porém, como diz Türche (1993), o intelecto não pode fazer funcionar o seu agir sem a conceituação, sem o aparato lógico, sem a certeza da solidez, mas a teia conceitual não é plausível de credibilidade, já que a própria consciência pode enganar a si mesma.

O intelecto, esse mestre da dissimulação, permanece tanto livre e isento da sua normal servidão [...] quando possuído de prazer criativo, mistura as metáforas e remove os pétreos limites das abstrações... (Nietzsche, 1997, p. 230).

O intelecto pode ser visto como o lugar do "brincar", podendo se valer da sua ousadia inventiva, que torna o homem criador, artista, menos pesado, na medida em que o liberta da teia conceitual e produz aparências, ficções e ilusões. 


\section{Observatónio}

ISSN n² 2447-4266

Vol. 4, n. 1, Janeiro-Março. 2018

DOI: http://dx.doi.org/10.20873/uft.2447-4266.2018v4n1p42

O esforço que Nietzsche elabora para compreender o mundo por traços fisiológicos, humanos, estabelecendo um valor aos processos criativos e transfiguradores, mostra o quanto o filósofo faz uso do seu procedimento de inversão. Pode-se dizer que a mentira da verdade seria querer encontrar a essência, o fundamento da vida e do mundo negando a aparência, o falso e o ilusório, enquanto a verdade da arte é acreditar na aparência como aparência (MACHADO, R. 1999). Ou melhor, enquanto o homem tem na verdade um meio de encontrar o fundamento, a essência do que seja verdadeiro e vital, a superioridade do conhecimento artístico sobre a verdade é não fazer oposição entre verdadeiro e falso, verdade e ilusão, verdade e aparência (MACHADO, 1999). A arte deseja apenas fazer valer a vida em sua plenitude, em seu poder inventivo e criador.

O que se pode notar como avesso entre conhecimento verdadeiro, ciência e arte nada mais é do que lutas de forças e de comandos. O que a arte pretende é afirmar a vida em todo seu processo criador e inventivo e o conhecimento, que se coloca como verdade nega a vida em criação. Diante dessa luta, o que Nietzsche leva em consideração é a arte, mas isso não significa pura negação do conhecimento, sua perspectiva é que arte estabeleça o valor para o conhecimento, ou tentar ao menos dominar aquilo que se pode chamar de "vontade de verdade" (MACHADO, R. 1999).

Nesse suposto conflito trágico entre verdade e aparência, verdade e não verdade, verdade e arte, a vida é ficção ou mesmo ilusão e, então, assume o valor supremo e irredutível. Com isso, aquilo que se chama de verdade nada mais é que um esforço antropomórfico para se falar do conhecimento. Ora, mas a vida, segundo Nietzsche é o encontro com o trágico, e os processos artísticos não deixam de dominar a vida, sendo ela mesma a própria inocência. Com isso, 


\section{Observatónio}

ISSN n² 2447-4266

Vol. 4, n. 1, Janeiro-Março. 2018

DOI: http://dx.doi.org/10.20873/uft.2447-4266.2018v4n1p42

não caberia pensar a verdade como representação, visto que essa imagem traz à vista todos os processos dogmáticos, aniquiladores da vida e do homem. A vontade desenfreada pela verdade, pelo conhecimento, pelo saber verdadeiro edifica uma vida em que o corpo é confiscado pela racionalidade exacerbada e definha a vida junto com seu poder criador.

Reabilitar a arte, a ilusão, a aparência é, em todo caso, dizer sim à vida e se contrapor a todo tipo de hipertrofia existencial. A vida tem necessidade de ficção porque é ficção e de maneira alguma há fundo essencial que nos permita dizer o que é, pois onde se pode encontrar a verdade em tudo aquilo é vida? Que "vontades de verdades" levam a ter tanto medo da ideia de verdade como ficção? Seria porque à verdade só caberia profundidade na superfície da "pele" que nela habita? Algumas questões são interessantes não por suas respostas, mas por permanecerem abertas e suspensas aos exercícios e perspectivas. Por isso, essa nota ensaísta não pretende dizer, mas simplesmente brincar com o pensamento, tendo como inspiração, Nietzsche, o grande pensador nômade, no dizer de Deleuze (1985); aquele que faz as palavras rodopiar, turbilhonar e os sentidos serem multiplicados diante do experimentalismo da sua filosofia.

\section{Referências}

$A B E L$, G. Verdade e interpretação. In: Cadernos Nietzsche, n. 12, p. 26. 117. São Paulo: 2002.

ARISTÓTELES. Metafísica (I e II). Tradução de Marcelo Perine, da versão italiana de Giovanni Reale. São Paulo: Loyola, 2002.

ABBAGNANO, N. Dicionário de Filosofia. Tradução e revisão de Ivone Castilho Benedetti. São Paulo, 2000.

DELEUZE, G. Pensamento Nômade. Tradução de Milton Nascimento e Sônia Salzstein Goldberg. São Paulo: Ed. Brasiliense, 1985. 


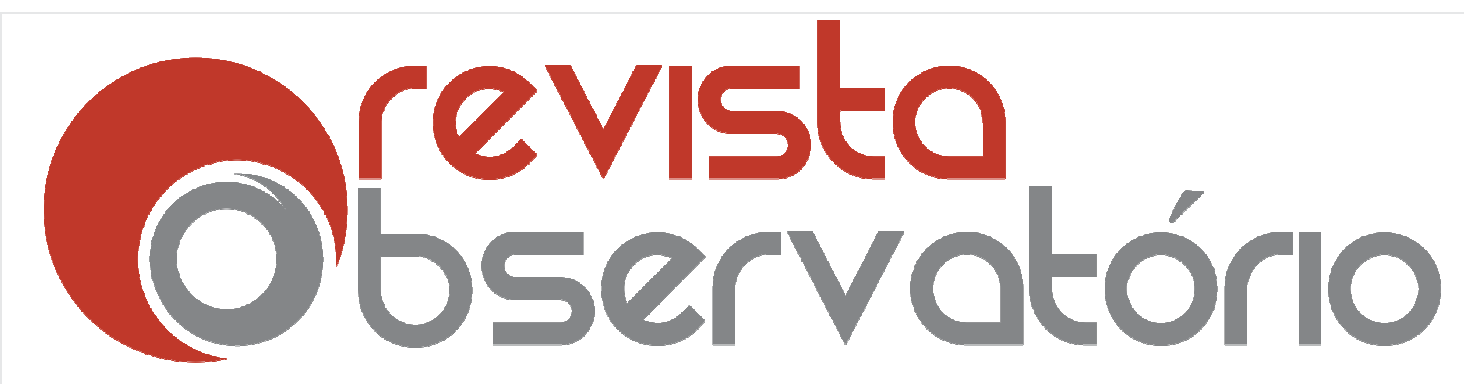

ISSN n² 2447-4266

Vol. 4, n. 1, Janeiro-Março. 2018

DOI: http://dx.doi.org/10.20873/uft.2447-4266.2018v4n1p42

FINK. E. $A$ filosofia de Nietzsche. Tradução de Joaquim Lourenço Duarte Peixoto. Lisboa, Editorial Presença, 1988.

MACHADO, R. Nietzsche e a verdade. Rio de Janeiro: Ed. Paz e Terra, 1999.

NIETZSCHE, F. Acerca da verdade e da mentira no sentido extramoral. Tradução de Helga Hooch Quadrado. Lisboa. Ed. Relógio'água, 1997.

- Nascimento da Tragédia ou helenismo e pessimismo.

Tradução de J. Guinsburg. São Paulo: Companhia das Letras, 1992.

Flammarion, 1969.

Das Philosophenbuch/Le livre du philosophe, Paris, Aubier

PLATÃO. Parmênides. Texto estabelecido e anotado por John Burnet; Tradução, apresentação e notas de Maura Iglésias e Fernando Rodrigues. Rio de Janeiro: Ed. PUC-Rio; São Paulo: Loyola, 2003.

PLATÃO. Crátilo. Tradução e textos complementares. Edson Bini. Bauru/São Paulo: Edipro, 2010.

TURCHE C. Niezsche: O louco e mania da razão. São Paulo: Vozes, 1993. 